\title{
Hounsfield units, echogenicity and T2 signals: Imaging of cystic structures in the mediastinum
}

\author{
Alain Tremblay MDCM
}

\begin{abstract}
A 57-year-old man presented with an incidental finding of a right A paratracheal mass. Computed tomography (CT) of the chest revealed a well demarcated, homogenous lesion $3 \mathrm{~cm}$ in size in the right paratracheal area (Figure 1). Bronchoscopy with endobronchial ultrasonography (EBUS) was performed with the intent of obtaining cytopathological samples. EBUS imaging revealed an anechoic lesion with negative Doppler signal. The lesion was believed to be consistent with a mediastinal cyst and, therefore, biopsies were not performed. Magnetic resonance imaging confirmed a fluid-filled structure and repeat CT imaging at one year showed stability in the lesion.
\end{abstract}

Video (go to www.pulsus.com): Linear endobronchial ultra.11- sound $(7.5 \mathrm{mHz})$ examination of right paratracheal lesion. Anechoic appearance of lesion with evidence of septation is demonstrated. Absence of flow on Doppler signal excludes a vascular structure, although a vessel is seen distal (left) of the lesion.

\section{KEY LEARNING POINTS}

- Mediastinal cysts should be included in the differential diagnosis of middle mediastinal masses.

- Clues to the diagnosis can be obtained by recognition of fluid density of the lesion. On CT, this can be detected by a Hounsfield unit (HU) measurement close to water ( $<20 \mathrm{HU})$; while on magnetic resonance imaging, an intense T2 signal is suggestive. EBUS can also be diagnostic when an anechoic lesion is identified with negative Doppler flow (1).

- If a mediastinal cyst is suspected, sampling or biopsy should be avoided to avoid introducing infection (2).

\section{REFERENCES}

1. McAdams HP, Kirejczyk WM, Rosado-de- Christenson ML, Matsumoto S. Bronchogenic cyst: Imaging features with clinical and histopathologic correlation. Radiology 2000;217:441-6.

2. Diehl DL, Cheruvattath R, Facktor MA, Go BD. Infection after endoscopic ultrasound-guided aspiration of mediastinal cysts. Interact CardioVasc Thorac Surg 2010;10:338-40.
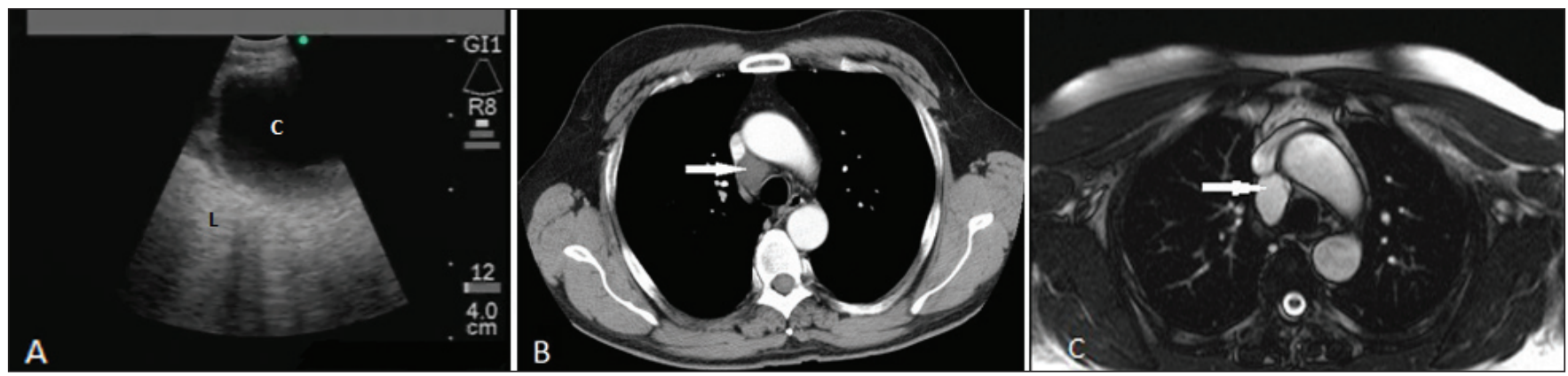

Figure 1) A Endobronchial ultrasound image of the lesion, demonstrating anechoic internal structure (C) with lung tissue ( $L$ ) deep to the lesion (to view video, go to www.pulsus.com). B Contrast-enhanced axial chest computed tomography demonstrating a homogeneous mass, 3 cm in size in the right paratracheal area (white arrow). The lesion was measured at 11 Hounsfield units. C Transverse axial image from a T2-weighted pulse sequence magnetic resonance image of lesion (white arrow), which displays hyperintense signal compatible with a cyst

The 'Images in Respiratory Medicine' section of the Canadian Respiratory Journal aims to highlight the importance of visual interpretation, whether physiological, radiological, bronchoscopic, surgical/thorascopic or histological, in the diagnosis of chest diseases. Submissions should exemplify a classic, particularly dramatic or intriguing presentation of a disease while offering an important educational message to the reader (insightful diagnostic pearls or differential diagnosis, etc). This section is not intended to be a vehicle for publication of case reports (see the Clinical-Pathologic-Conferences for case-based leaning series).

Department of Medicine, University of Calgary, Calgary, Alberta

Corresponence: Dr Alain Tremblay, Department of Medicine, University of Calgary, 3330 Hospital Drive Northwest, Calgary Alberta T2N 4N1.

Telephone 403-210-3866, fax 403-944-1577, e-mail alain.tremblay@ucalgary.ca 


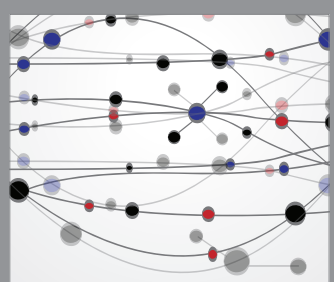

The Scientific World Journal
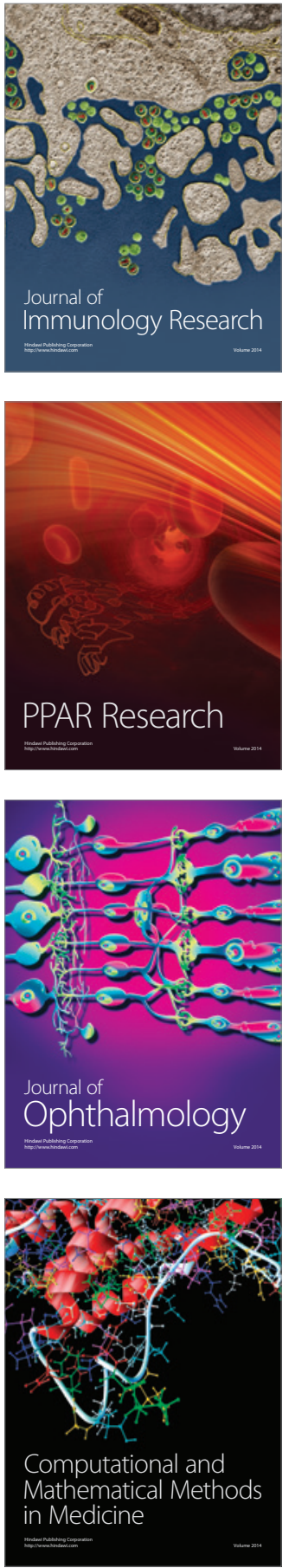

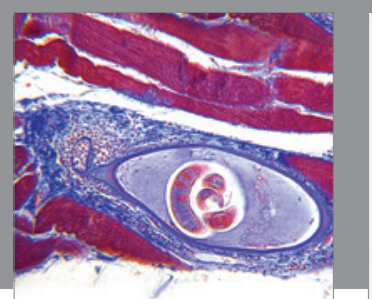

Gastroenterology Research and Practice

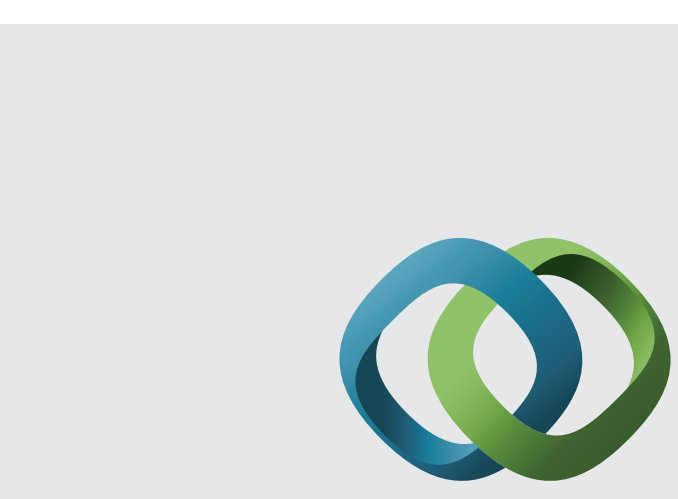

\section{Hindawi}

Submit your manuscripts at

http://www.hindawi.com
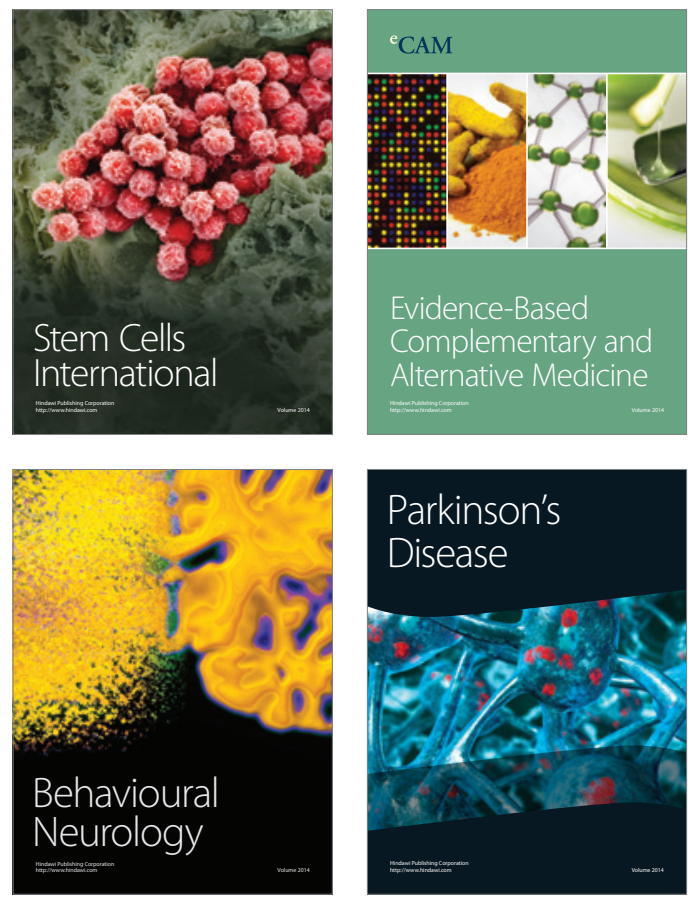
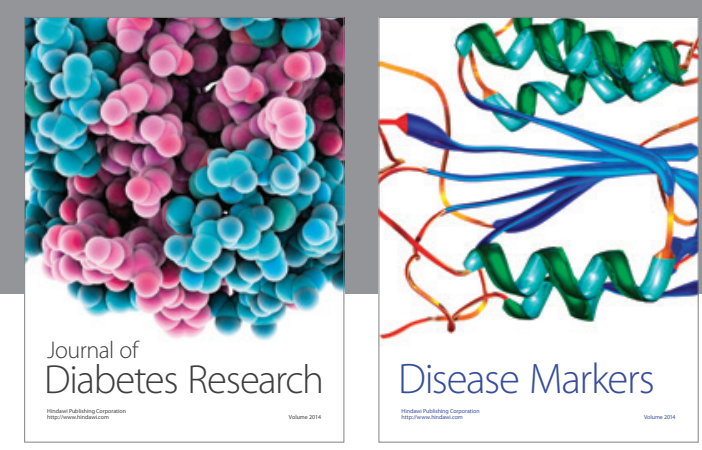

Disease Markers
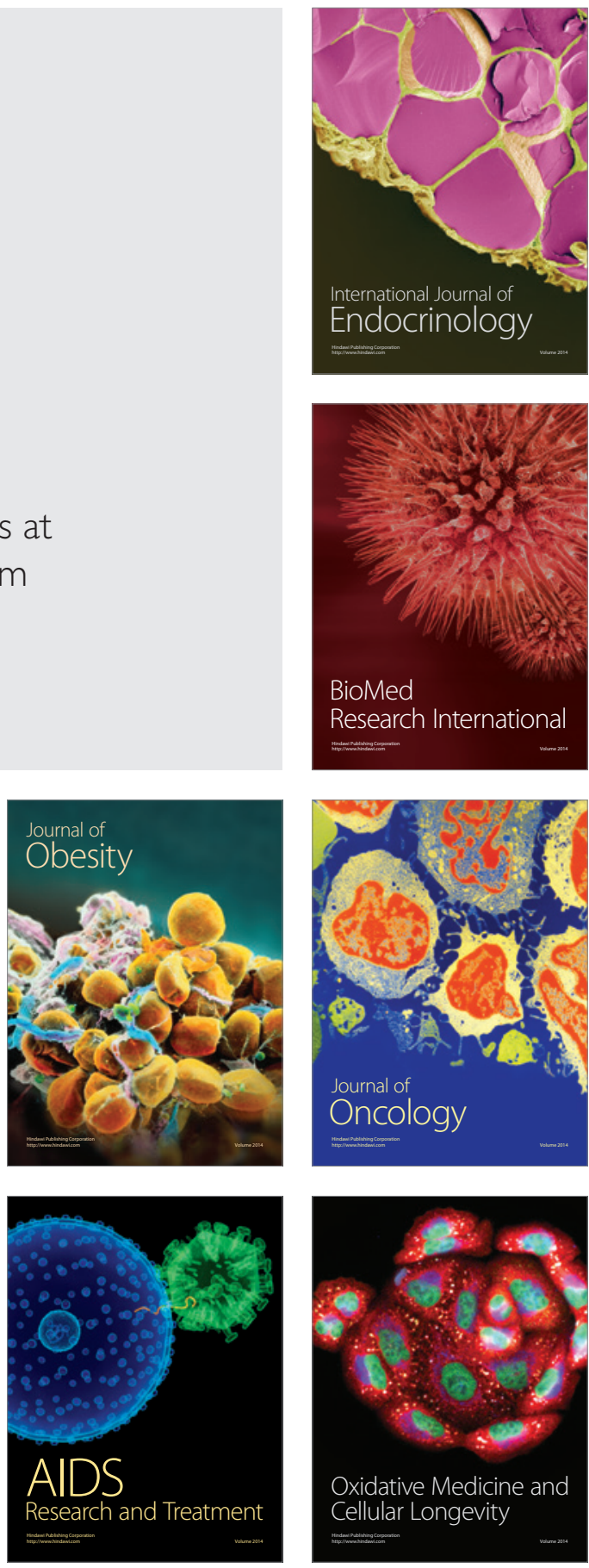